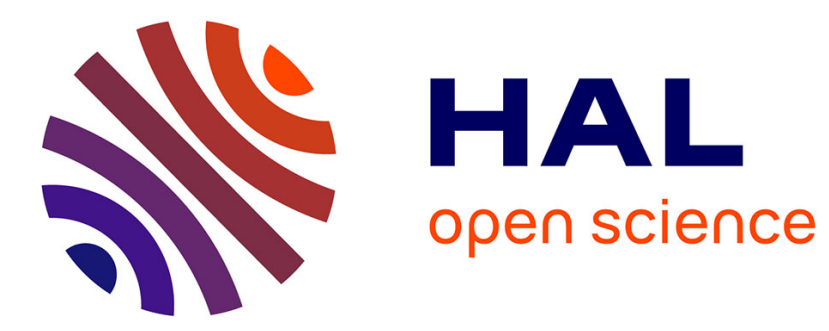

\title{
Coordination complexes involving sydnones as ligands
}

Xavier Bantreil, Nicolas Pétry, Frédéric Lamaty

\section{To cite this version:}

Xavier Bantreil, Nicolas Pétry, Frédéric Lamaty. Coordination complexes involving sydnones as ligands. Dalton Transactions, 2019, 48 (42), pp.15753-15761. 10.1039/c9dt03115d . hal-02370898

\section{HAL Id: hal-02370898 \\ https://hal.science/hal-02370898}

Submitted on 7 Dec 2020

HAL is a multi-disciplinary open access archive for the deposit and dissemination of scientific research documents, whether they are published or not. The documents may come from teaching and research institutions in France or abroad, or from public or private research centers.
L'archive ouverte pluridisciplinaire HAL, est destinée au dépôt et à la diffusion de documents scientifiques de niveau recherche, publiés ou non, émanant des établissements d'enseignement et de recherche français ou étrangers, des laboratoires publics ou privés. 


\title{
Coordination complexes involving sydnones as ligands
}

\author{
Xavier Bantreil, (D) * Nicolas Pétry (DD) and Frédéric Lamaty (D)*
}

Sydnones are mesioionic compounds studied for years for their versatile reactivity in substitution reactions, sydnone-alkyne or sydnone-alkene cycloaddition reactions. This perspective article focuses on the use of sydnones in coordination complexes, either through a metalation on one of the carbons of the sydnone ring, its modification to obtain polydentate ligands, or its use as a polar moiety that could influence the properties of the final complex. Such compounds are valuable either from a synthetic point of view or for their biological properties.

\section{Introduction}

Sydnones, originally discovered by Earl and Mackney in $1935,{ }^{1}$ are mesoionic compounds that have attracted significant interest in recent years, particularly with the discovery of the copper-catalyzed 1,3-dipolar sydnone-alkyne cycloaddition $(\mathrm{Cu}$ $\mathrm{SAC}$ ) and its use in bioconjugation. ${ }^{2}$ These heterocycles are also potentially of interest for their biological properties, such as their antibacterial, antifungal, anti-inflammatory or antineoplastic activity. ${ }^{3}$ Due to their particular electronic structure, sydnones are classified as a subclass of mesomeric betaines. ${ }^{4}$ As defined by IUPAC, mesoionic compounds are "dipolar five(possibly six-) membered heterocyclic compounds in which both the negative and the positive charge are delocalized, for which a totally covalent structure cannot be written, and which cannot be represented satisfactorily by any one polar structure. The formal positive charge is associated with the ring atoms, and the formal negative charge is associated with ring atoms or an exocyclic nitrogen or chalcogen atom". Among eight resonance structures of sydnones, the most used in the literature is form I (Fig. 1), in which the positive charge is located on the $\mathrm{N}_{3}$ and the negative charge on the exocyclic oxygen $\mathrm{O}_{6}$. Such a structure was originally drawn to represent the aromaticity of the heterocycle. Indeed, calculated bond orders (A) suggested an enolate character of the exocyclic oxygen. ${ }^{6}$ However, calculated net charges $\left(\mathbf{B},{ }^{7} \mathbf{C}^{8}\right)$ and scaled dipolemoment representation $\mathbf{D}$ indicated a large negative charge on the exocyclic oxygen, and more importantly a rather small negative charge on $\mathrm{C}_{4}$, inconsistent with a nucleophilic enolate. Since these calculations, performed in the middle of

Institut des Biomolécules Max Mousseron (IBMM), UMR 5247, CNRS, Université de Montpellier, ENSCM, Campus Triolet, Place Eugène Bataillon, 34095 Montpellier Cedex 5, France. E-mail: frederic.lamaty@umontpellier.fr, xavier.bantreil@umontpellier.fr the $20^{\text {th }}$ century, NICS (nucleus-independent chemical shift) ${ }^{9}$ value of $N$-phenylsydnone was calculated at $-6.8 .{ }^{10}$ In comparison, cyclopentadienyl anion and cyclopentane have NICS values of -12.3 and -2 , respectively, demonstrating sydnone is not aromatic. The double bond character, even if consistent with a $\mathrm{C}=\mathrm{O}$ stretching band $\left(\nu \approx 1730 \mathrm{~cm}^{-1}\right)$, was rejected in the early studies because of the particular mesoionic structure of sydnones. However, studies based on XRD (X-ray diffraction) analysis, IR measurements and electronic density calculations demonstrate that (i) the exocyclic $\mathrm{C}-\mathrm{O}$ bond has indeed a double bond character, (ii) the $\pi$ electrons are unequally delocalized on the sydnone ring, and (iii) the $\mathrm{N}_{2}-\mathrm{N}_{3}$ and $\mathrm{N}_{3}-\mathrm{C}_{4}$ bonds have partial double bond character. ${ }^{10,11}$ Thus, representations II and III (Fig. 1) may be more consistent with the gathered data. Additionally, in XRD data obtained from 4-substituted-sydnones, the $\mathrm{C}_{4}$-substituent bond is found in the plane of the sydnone, ${ }^{12}$ thus showing an sp2 character for $\mathrm{C}_{4}$, at least in the solid state. Thus, in the rest of this article, we decided to use representation III, which is in agreement with such observation.

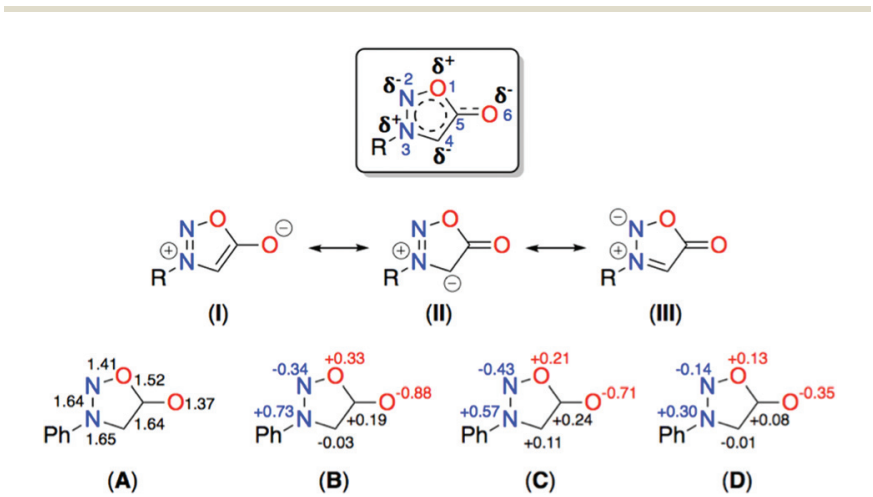

Fig. 1 Mesomeric structures of sydnones, calculated bond orders (A) and net charges $(B-D)$. 


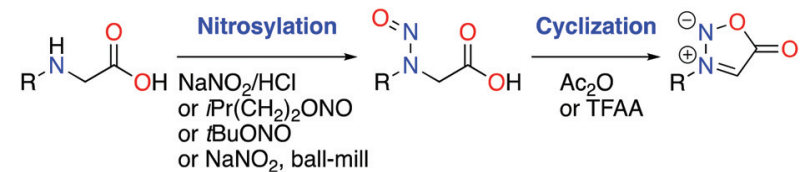

Scheme 1 Different existing synthetic methods for the preparation of sydnones.

Since the first report, ${ }^{1}$ sydnone synthesis from $\alpha$-amino acids (Scheme 1) involves a nitrosylation step, using sodium nitrite together with concentrated $\mathrm{HCl}$ or isoamyl nitrite, ${ }^{13}$ and subsequent cyclization using acetic or trifluoroacetic anhydride (TFAA). ${ }^{14}$ Specklin et al. recently showed that it was possible to work under solvent-free conditions, using tert-butylnitrite and TFAA. ${ }^{15}$ However, sydnones were not isolated but directly engaged in a $\mathrm{Cu}-\mathrm{SAC}$ reaction to furnish corresponding pyrazoles. In 2019, our group developed a one-pot two-step mechanochemical synthesis of sydnones. ${ }^{12 h}$ Notably, the nitrosylation step was performed using sodium nitrite without acid, the protons necessary for the reaction arising from the amine and acid functions of the $\mathrm{N}$-arylglycine substrate.

As described above, the application of sydnones in organic synthesis and cell biology are increasingly topical. Nevertheless, the involvement of sydnones in coordination chemistry is less studied. This report will focus on coordination complexes featuring sydnones as ligands, either directly linked to the metal or involved in the structure of the ligand.

\section{Metalation at $\mathrm{C}_{4}$}

Several examples are reported in literature regarding the formation of sydnonyl-metal complexes with a $\mathrm{C}_{4}$-metal bond formed either directly or through a deprotonation step. Mercuration of $N$-(3-pyridyl)sydnone $\mathbf{1}$ was realized in the presence of mercury(II) chloride and excess sodium acetate. ${ }^{16}$ Interestingly, in most of the solvents, reaction led to the coordination of the pyridine onto mercury (compound 2). However, reaction in ethanol with a short reflux furnished the heteroleptic mercury complex 3 while a longer reaction provided the homoleptic 4 (Scheme 2, top). This strategy was latter used to effect the iodination of $N$-(2-aminophenyl) sydnone after a mercuration step, ${ }^{17}$ or to perform cross couplings, using palladium chloride and cuprous chloride, and obtain dimers or cyclodimers like compound 5 (Scheme 2, bottom). ${ }^{18}$

In 1988, 4-copper-3-phenylsydnone 7 was generated in situ from deprotonation of the parent sydnone 6 with butyl lithium, followed by transmetallation with copper(I) bromide. ${ }^{19}$ Such product was found to be more stable in solution than the lithiated species and participated in palladiumcatalyzed cross-coupling reactions, to yield sydnones $\mathbf{8}$ substituted in position $\mathrm{C}_{4},{ }^{19,20}$ or the formation of $\sigma$-sydnon-4-ylcyclopentadienyl(dicarbonyl)iron 9 (Scheme 3, top). The same group also reported the formation of the zinc intermediate species 10 to introduce substituents at $\mathrm{C} 4 .{ }^{20 a}$ However, reaction was less efficient than with the copper derivative and proceeded only with 4-nitroiodobenzene and bromostyrene as coupling partners (Scheme 3, bottom).

The Kalinin group also reported the synthesis of Ni, Pd and Pt derivatives of sydnones. ${ }^{21}$ Oxidative addition of 4-bromo-3phenylsydnone ${ }^{22} \mathbf{1 1}$ to palladium tetrakis(triphenylphosphine) yields the corresponding palladium complex as a trans/cis mixture (Scheme 4). On the other hand, reactions with platinum or nickel give only the complexes with a trans configuration. Interestingly, reaction of the complexes with carbon monoxide resulted in $\mathrm{CO}$ insertion into the sydnone-metal

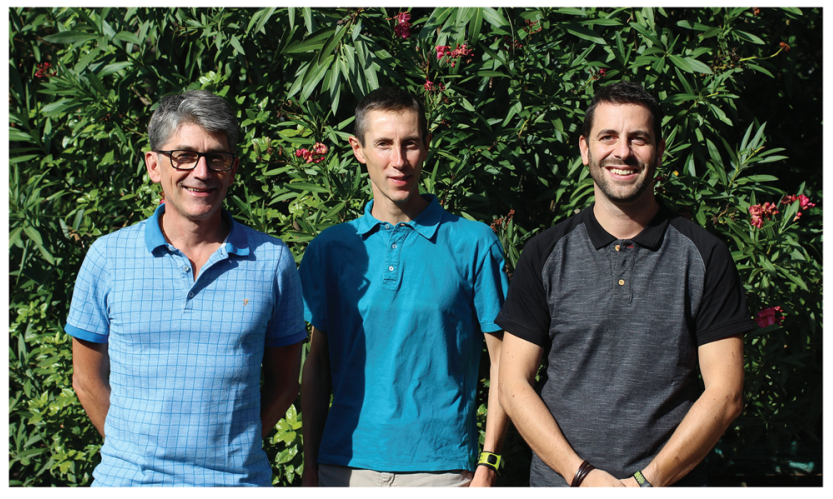

From left to right: F. Lamaty, N. Pétry and X. Bantreil

$X$. Bantreil obtained his PhD in 2008 from UPMC (Paris) working with Prof. G. Poli. He then took a post-doctoral position at St Andrews University (UK, Prof. S. P. Nolan and Dr C. S. J. Cazin), before joining in $2010 \mathrm{Dr}$ P. Belmont at Institut Curie (Paris) for a 1-year post-doctoral position. In
2011, he obtained an assistant professor position in Montpellier.

N. Pétry achieved a Ph.D. in 2007 at ICSN (Gif-sur-Yvette) with Prof. J.M. Campagne. In 2009, he worked for 10 months in consultancy about the REACH regulation and then joined CNRS as engineer in Gif-sur-Yvette. In 2012 he went to Nancy in the group of Prof. Y. Fort (biomolecules for medical imaging applications). In 2015, he moved to Montpellier to work on Green Chemistry.

F. Lamaty received his Ph.D. in 1992 from Purdue University (West Lafayette, IN USA) under the supervision of Prof. Ei-chi Negishi. He then joined (Rhône-Poulenc funding) the group of Professor M. Julia at the Ecole Normale Supérieure in Paris (synthesis of Vitamin A). In 1994, he obtained a permanent position at CNRS. Since 2011 he has been heading the Green Chemistry and Enabling Technologies team at the Max Mousseron Institute for Biomolecules (IBMM).

Their research interests focus on the synthesis of high value molecules (peptides, heterocycles, coordination complexes...), while developing sustainable approaches (flow chemistry, mechanochemistry). 


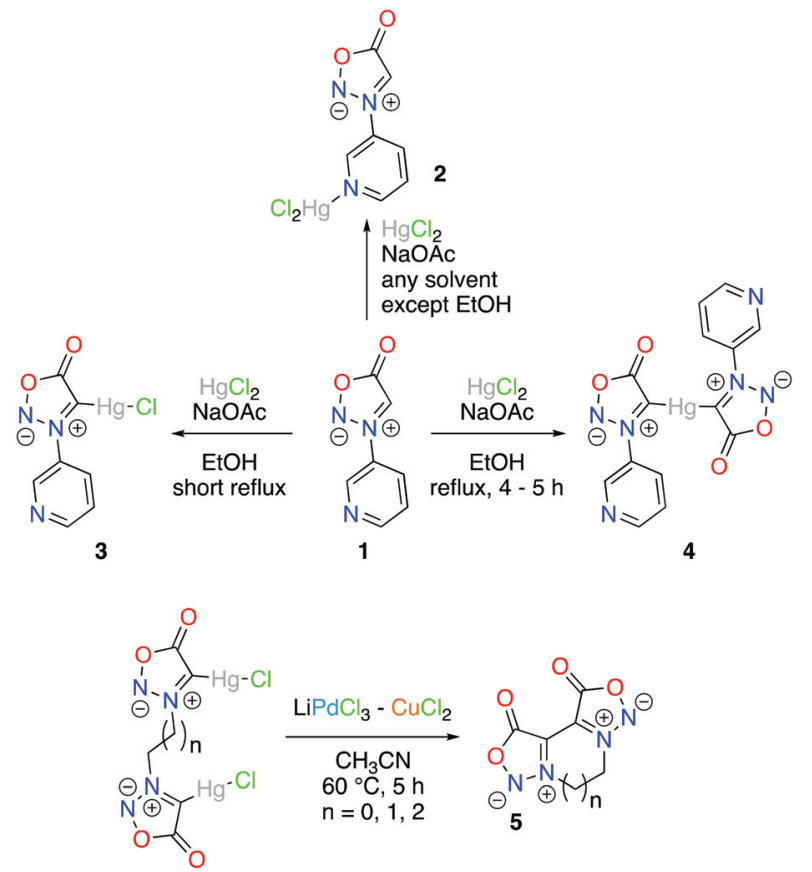

Scheme 2 Mercuration of the sydnone ring and its use in self crosscoupling reactions.

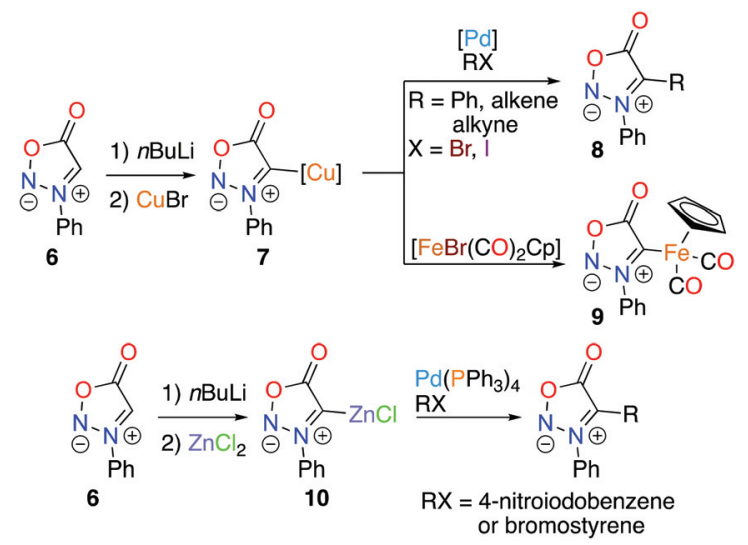

Scheme 3 In situ generation of sydnonyl copper and zinc species and further reactions.

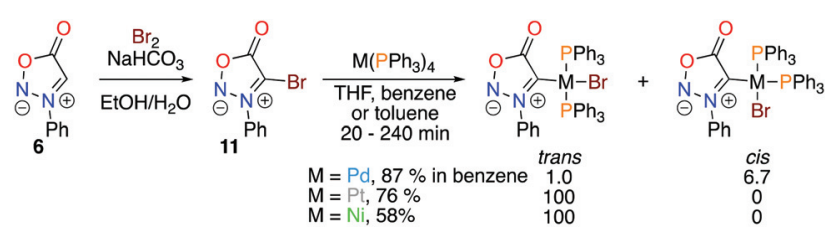

Scheme 4 Oxidative addition to palladium, platinum and nickel.

bond, as confirmed by IR spectroscopy. ${ }^{21 b, 23}$ However, these acyl-metal compounds were relatively unstable and could not be isolated in their pure form. Of note, reaction of 4-chloromercury-3-phenylsydnone $\mathbf{1 2}$ with nickel tetrakis (triethyl-

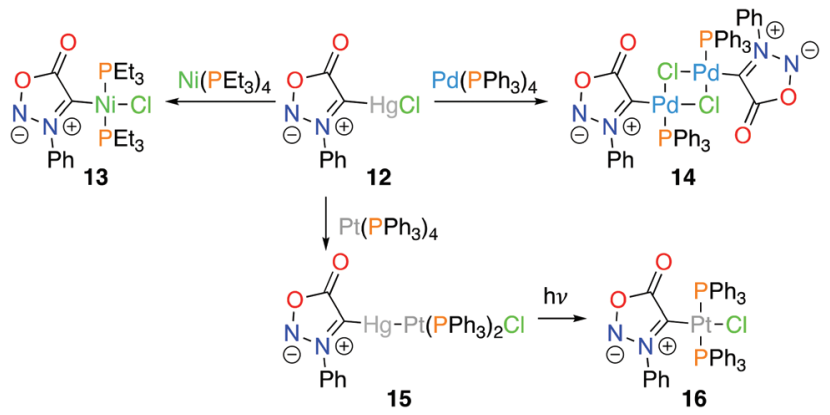

Scheme 5 Reactivity of sydnonylmercury chloride with different transition metals.

phosphine) furnished the chloride sydnonyl nickel complex 13 (Scheme 5, left). With palladium tetrakis(triphenylphosphine) a dimeric structure $\mathbf{1 4}$ was isolated (Scheme 5 , right), while in the presence of a platinum, stable bimetallic complex 15 was obtained, which upon UV irradiation underwent a demercuration step providing the sydnonylplatinum chloride complex $\mathbf{1 6}$ (Scheme 5, bottom).

More recently, the Taran group developed the synthesis of palladium complexes featuring either phosphines (17) or substituted bipyridines (18) as ancillary ligands in a view to produce readily 3-fluorosydnones (Scheme 6). ${ }^{24}$ Interestingly, solely bipyridine-containing complexes reacted with Selecfluor to furnish the desired 3-fluorosydnone. As obtaining pure 3-fluorosydnone proved challenging, the Cu-SAC was performed on the crude reaction mixture, leading to 5-fluoro-1,4-pyrazoles 19.

The Schmidt group studied sydnone anions as $\mathrm{N}$-heterocyclic carbenes (NHC). ${ }^{10,25}$ Upon reaction with cyanomethyllithium, deprotonated 4 -arylsydnones 20 could be isolated (Scheme 7). Interestingly, ethylation of the exocyclic oxygen of 6 furnished $O$-ethylsydnone, precursor of an abnormal NHC (aNHC, also known as mesoionic NHC). Deprotonation of $O$-ethylsydnones proved unsuccessful and resulted in decomposition. Calculated HOMO of $\mathbf{2 0}$ and of the anion of $O$-ethyl- $N$-phenylsydnone were quite different. HOMO of 20 was more a $\pi$-orbital, with a large coefficient at $\mathrm{C}_{4}$, while HOMO of the latter was more $\sigma$-type, as in aNHC. However, direct metalation of the anions was unsuccessful and corres-

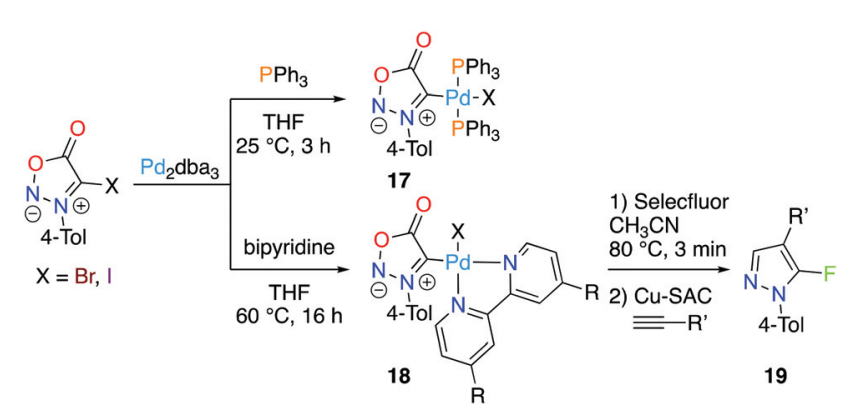

Scheme 6 Synthesis of palladium complexes for efficient fluorination reaction. 


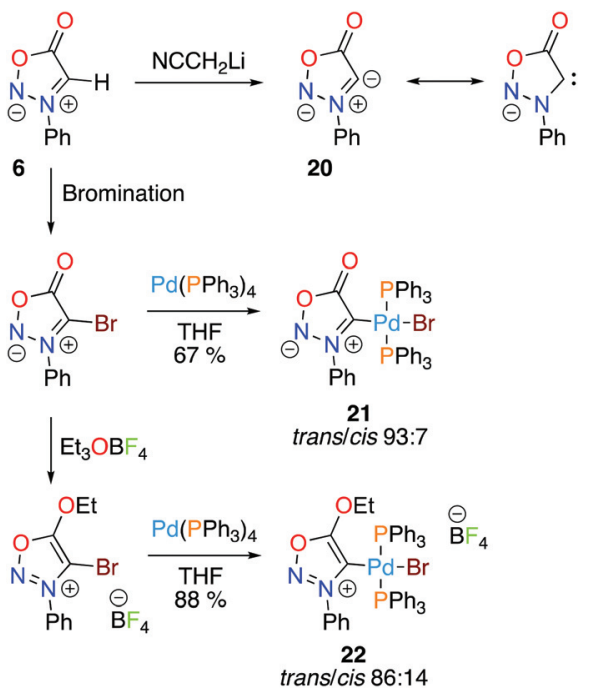

Scheme 7 Generation of sydnone anion NHC and novel aNHC palladium complex.

ponding palladium complexes 21 and 22 were obtained using the method described previously, i.e. bromination at $\mathrm{C}_{4}$ and subsequent oxidative addition to palladium tetrakis(triphenylphosphine). Complexes $\mathbf{2 1}$ and $\mathbf{2 2}$ were found to be more efficient in the Suzuki-Miyaura cross-coupling reaction than classical $\mathrm{Pd}^{0}$ and $\mathrm{Pd}^{\mathrm{II}}$ salts. ${ }^{10,25,26}$ Of note, the same group also studied the generation of an anionic NHC derived from sydnone imines and corresponding metallic adducts. ${ }^{27}$

\section{Sydnone-containing polydentate ligands}

Sydnones were also modified to act as bidentate ligands. The group of Wang described the use of sydnone as a P,C ligand. ${ }^{28}$ After deprotonation with $n$-butyl lithium of $N$-(4-methoxyphenyl)-sydnone and reaction with chloro(di-tert-butyl)phosphine, ligand 23 was isolated in $84 \%$ yield. Reaction with palladium(II) chloride and concentrated $\mathrm{HCl}$ in refluxing ethanol furnished compound 24, which was formed upon coordination of the phosphorus atom to the metal and $\mathrm{C}-\mathrm{H}$ insertion in the arylsydnone (Scheme 8, left). The structure was confirmed by XRD analysis. The $\mathrm{C}-\mathrm{C}$ bond lengths in the aryl moiety, ranging from 1.353 to $1.430 \AA$, proved the distortion in the aromatic system, and thus confirmed the $\mathrm{C}-\mathrm{H}$ insertion. Interestingly, the same group reacted similar phosphine ligands featuring either $N$-phenylsydnone instead of $N$-(4-methoxyphenyl)sydnone $^{29}$ or diphenylphosphine instead of di-tert-butylphosphine $^{30}$ with palladium(II) chloride. In these cases, no orthometalation through $\mathrm{C}-\mathrm{H}$ activation was observed and complex 25 was isolated (Scheme 8, right). Further reaction of the complex with different amines or phosphine/phosphite led to the displacement of one sydnonylphosphine ligand. In the reaction with amines, a trans arrangement was obtained in the final complexes 26 while it resulted in a cis-dichloro complex 27 with the phosphorus ligand.

The synthesis of bidentate diphenyl(2-diphenylphosphinophenylsydnonyl)phosphine ligand 28 and corresponding palladium complex 29 were also developed (Scheme 9). ${ }^{29,31}$ The bond lengths in the sydnone ring, upon coordination of $\mathbf{2 8}$ on palladium, substantially decrease, which is in correlation with
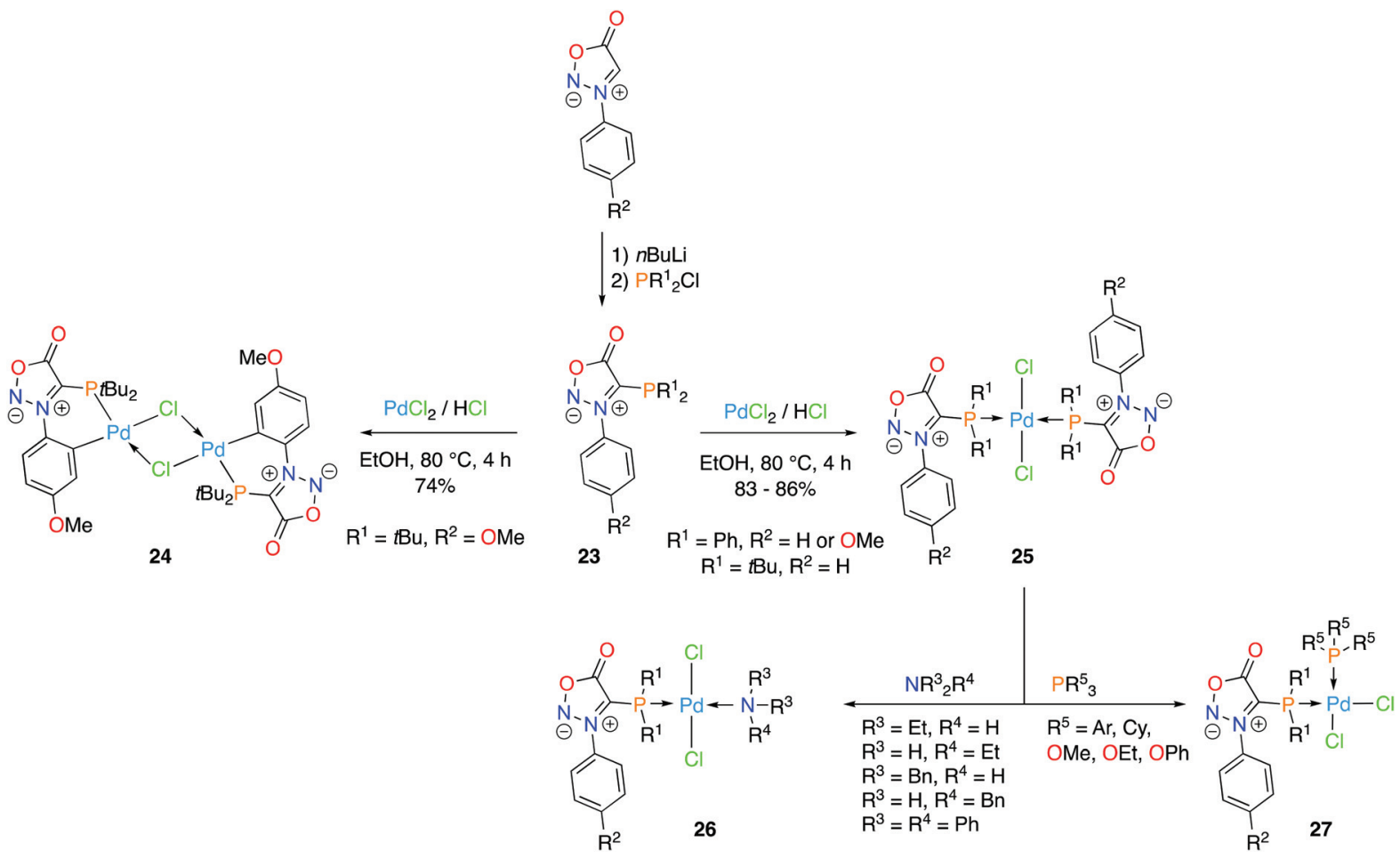

Scheme 8 Influence of the aryl moiety on $\mathrm{C}-\mathrm{H}$ insertion. 

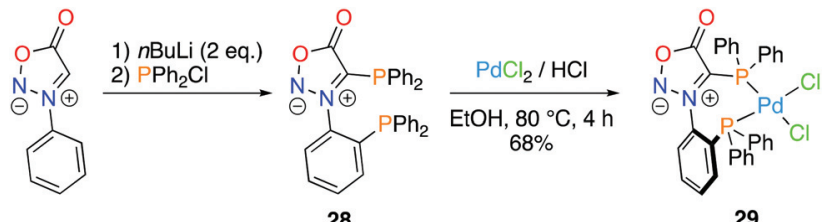

28

Scheme 9 Formation of a sydnonyldiphosphine-containing palladium complex.

the donation of electron density to the metal via the phosphorus atom. The decrease in bond length is much higher for the $\mathrm{C}_{\mathrm{Ph}}-\mathrm{P}$ bond than for the $\mathrm{C}_{\mathrm{Syd}}-\mathrm{P}$ bond, suggesting that the phenyl moiety is more donating than the sydnone to the phosphorus.

Shih et al. reported the synthesis of novel palladium complexes featuring 3-arylsydnone-4-carbaldehyde N(4)-phenylthiosemicarbazone $\mathbf{3 0}$ as ligand and tested their biological activity. $^{32}$ The different ligands were prepared from the condensation of 3-aryl-4-formylsydnone and 4-phenylthiosemicarbazide at $45{ }^{\circ} \mathrm{C}$ for several days in ethanol (Scheme 10). Subsequent metalation in the presence of potassium tetrachloropalladate for 7 days in methanol furnished the desired sydnone-palladium complexes 31. Interestingly, the exocyclic oxygen of the sydnone was involved in the chelation of palladium and acted as a two-electron donor rather than a single electron donor. This was demonstrated by the shift of the $\nu_{\mathrm{C}=\mathrm{O}}$ from $1745 \mathrm{~cm}^{-1}$ in the free ligand to lower wave number $1660 \mathrm{~cm}^{-1}$ in the complex. Thus ligand 30 was found to be a tridentate $O, N, S$-ligand, as shown by X-ray diffraction of complex 31 ( $\mathrm{Ar}=4$-Tol). Noteworthy, in the free ligand, the sulfur atom points away from the sydnone in the solid state (XRD analysis), while upon metal complexation, during which a deprotonation occurs, a change in configuration results in a tridentate ligand behavior. Additionally, the exocyclic $\mathrm{C}=\mathrm{O}$ bond slightly elongates from $1.211 \AA$ to $1.239 \AA$ in the complex (Table 2). Free ligands and corresponding complexes were tested for their anticancer activity against human hepatocellular carcinoma (HepG2) and human cervical epithelioid carcinoma (HeLa) cells. Introducing a metal might help in finding

novel active compounds without the resistance to chemotherapy involving 5-fluorouracil (5-FU). Gratifyingly, the complexes were found more active than both the free ligands and 5-FU, with $\mathrm{IC}_{50}$ values down to $0.77 \mu \mathrm{M}$ and $0.36 \mu \mathrm{M}$ for HepG2 and HeLa cells, respectively.

In 2019, Pétry et al. reported the mechanochemical synthesis of coordination complexes ${ }^{33}$ featuring a $N$-phenyl-(4pyridyl)sydnone 32 as $N, O$ ligand. ${ }^{12 h}$ Ball-milling enabled the efficient synthesis of $N$-arylglycines and corresponding sydnones, without the need for concentrated $\mathrm{HCl}$ during the nitrosylation step. After introduction of a pyridine at $\mathrm{C}_{3}$ using a palladium-catalysed cross-coupling, corresponding cobalt, copper and zinc complexes 33-36 were formed in $1 \mathrm{~h}$ of milling in a vibratory ball-mill (Scheme 11). Conversion was confirmed in the solid state by ex situ IR spectroscopy of the crude reaction mixture, with a shift of the $\mathrm{C}=\mathrm{O}$ stretching band from $\nu=$ $1757 \mathrm{~cm}^{-1}$ in the free ligand to lower wave numbers in the complexes $\left(\nu=1660-1726 \mathrm{~cm}^{-1}\right)$. Depending on the metal used, different structures were obtained (octahedral for cobalt with a dimeric structure 33, octahedral for copper 34-35 and tetrahedral for zinc 36) and confirmed by XRD analysis.

\section{Miscellaneous}

Sydnone is not always participating in the coordination of the metal. The first example of this kind was patented in 1970 and disclosed the formation of $\mathrm{N}$-(3-pyridyl)sydnone $\mathbf{1}$ and corresponding copper, nickel and iron complexes for applications as pigments (Scheme 12, top). ${ }^{34}$ Yet, the complexes were characterized only by their melting point and IR spectra. One could question the reported structures 37 in which the metal is chelated by the nitrogen atoms of the sydnone and the pyridine, geometrically difficult to picture considering the orbitals overlapping. Sydnone $\mathbf{1}$ may more probably act as a monodentate ligand, solely with a coordination of the pyridine, as shown by Lin et al. in the formation of penta(cyano)ferrate(II) complex 38 featuring the same $N$-(3-pyridyl)sydnone ligand (Scheme 12, bottom). ${ }^{35}{ }^{1} \mathrm{H}$ NMR analysis and comparison with complexes featuring differently substituted 3-pyridine ligands unequivocally rejects a possible metal/sydnone ring interaction.
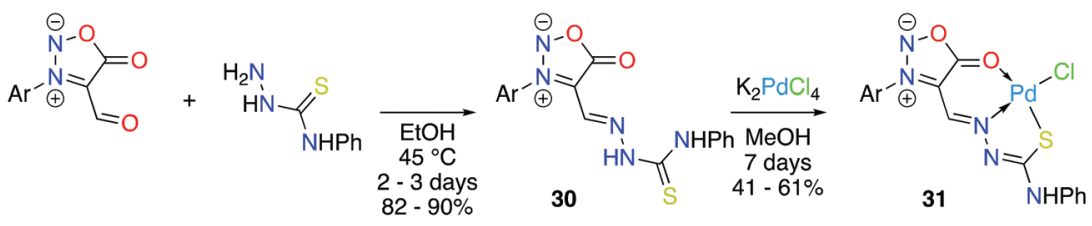

$\mathrm{Ar}=\mathrm{Ph}, 4-\mathrm{Tol}, 4-\mathrm{MeOPh}, 4-\mathrm{EtOPh}$
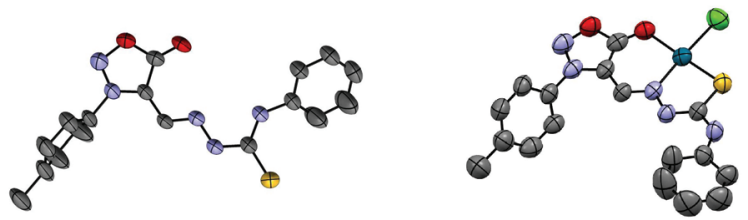

Scheme 10 Synthesis of palladium complexes with anticancer activity. 


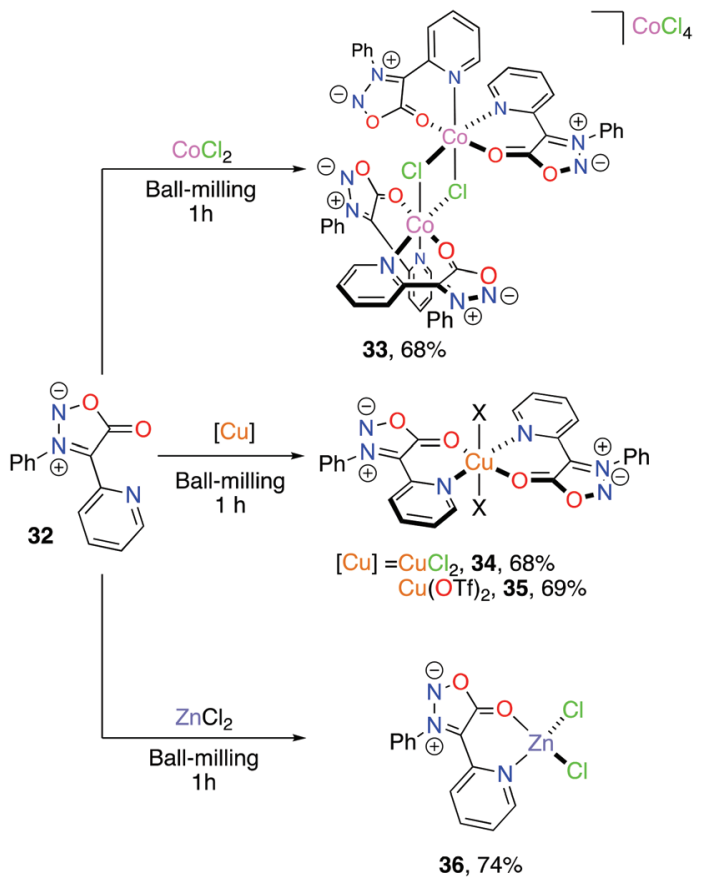

Scheme 11 Mechanosynthesis of $\mathrm{Co}, \mathrm{Cu}$ and $\mathrm{Zn}$ sydnone-containing complexes.

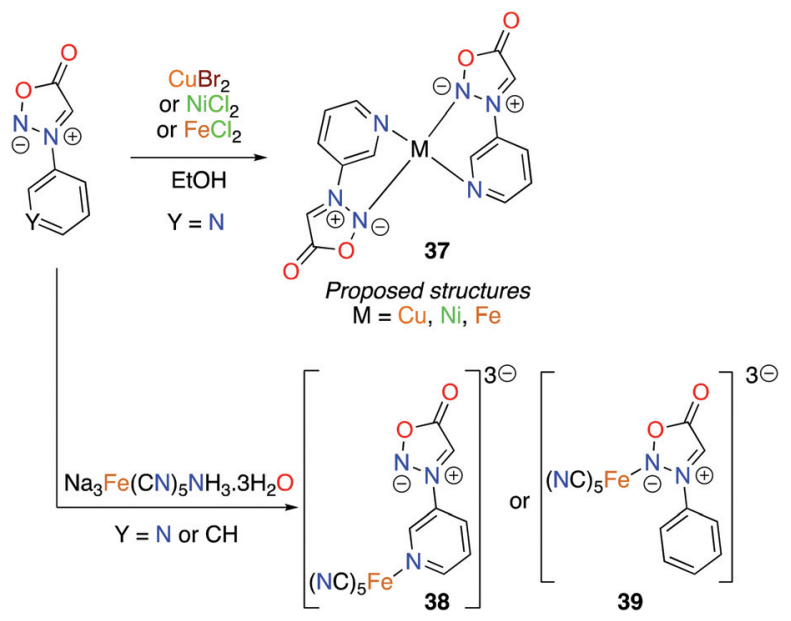

Scheme 12 Synthesis of copper, nickel and iron complexes.

Additionally, UV-Vis absorption and electrochemical analyses showed a $\pi$-stabilization of the complex due to the presence of the sydnone. The same group reported the reaction of $N$-methyl and $N$-phenylsydnones with penta(cyano)ferrate(II) to study the complexation of the sydnone heterocycle to a metal (Scheme 12). ${ }^{36}$ Even though it cannot be unambiguously proved, the authors propose coordination of iron by the $\mathrm{N}_{2}$ of the sydnone. Spectral and electrochemical studies of the complexes 39 suggest a stronger backbonding than for pyridine bound complexes of penta(cyano)ferrate(II).

In 2005, Cooper et al. synthesized sydnone-containing platinum acetylide oligomers $\mathbf{4 0}$ and demonstrated the influence of the sydnone on the spectroscopic properties of the compounds compared to similar sydnone-free oligomers (Fig. 2). ${ }^{37}$ The study of the compounds using ${ }^{13} \mathrm{C}$ NMR analysis demonstrated

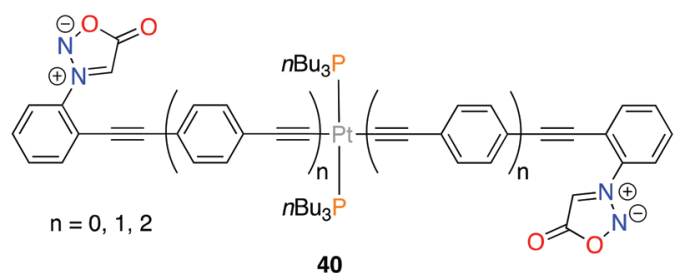

Fig. 2 Formation of sydnone-containing platinum acetylide oligomers.

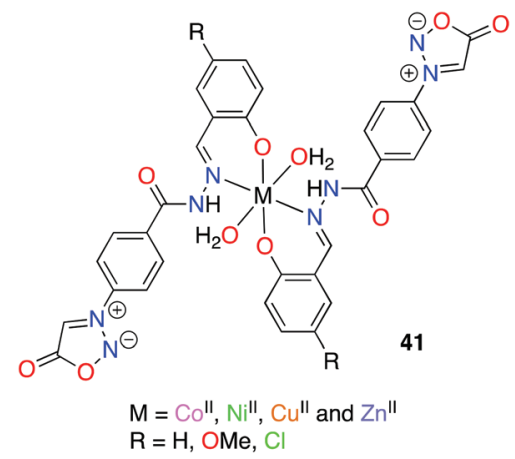

Fig. 3 Sydnonyl-Schiff base containing coordination complexes.

a)

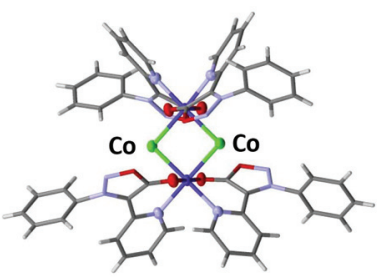

b)

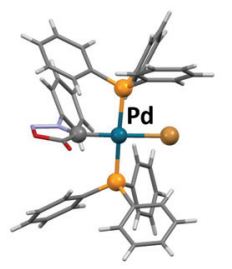

d)

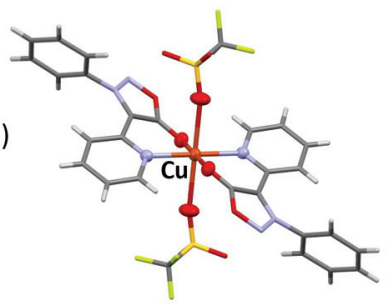

c)

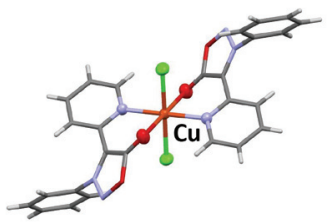

e)

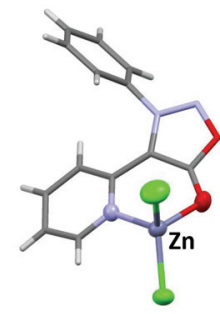

Fig. 4 X-ray structures of compounds (a) 33, (b) 21, (c) 34, (d) 35 and (e) 36 . 
an electronic interaction between the sydnone and the platinum. However, this interaction decreased in longer oligomers. The absorption spectra of the compounds showed that there is an influence of the sydnone ring, in the smaller oligomer $(n=0)$, suggesting that the ground-state absorption spectra of 40 may include ligand-centered transitions and MLCT

Table 1 Selected bond distances and angles for 42 and 21

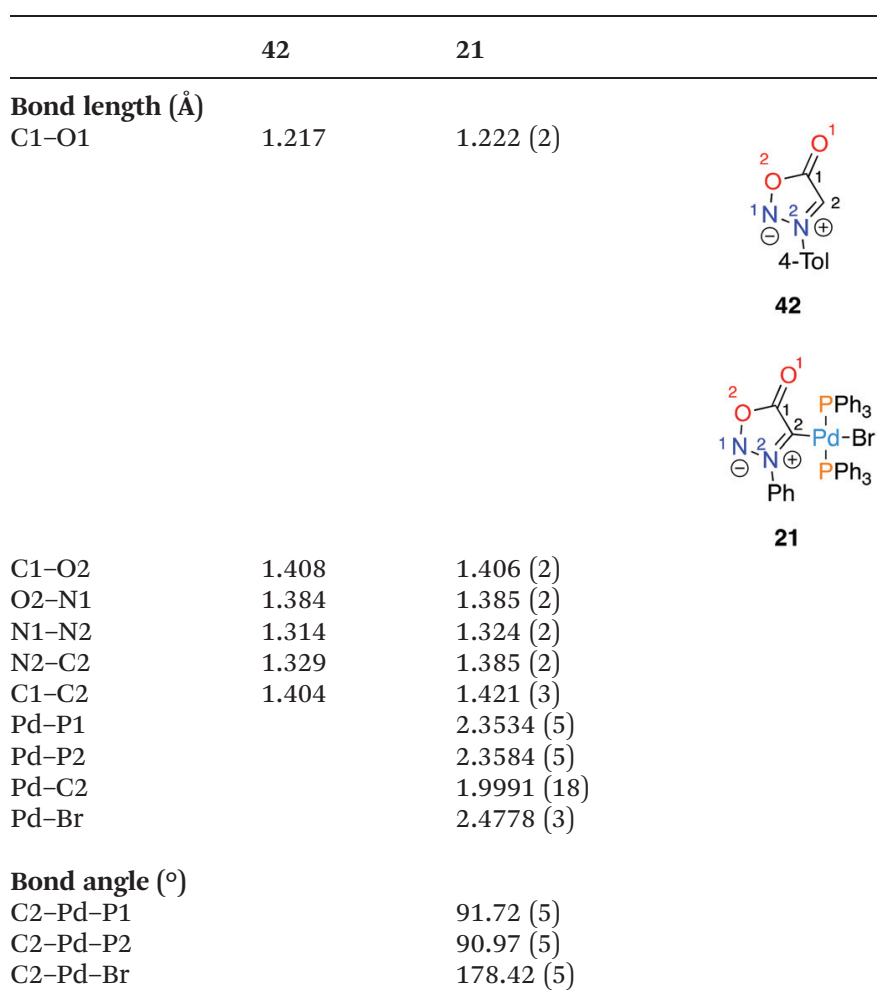

(metal to ligand charge transfer) transitions. The complexes have weak room temperature fluorescence but exhibit intense phosphorescence (after dissolving in 2-MeTHF, cooling and irradiating). Comparison with the sydnone-free oligomers outlined the contribution of the sydnone to fluorescence, which decreased in longer oligomers.

In 2008, Phaniband et al. described the synthesis of Schiff base ligands, featuring sydnone, and corresponding cobalt, nickel, copper and zinc complexes 41 (Fig. 3). ${ }^{38}$ Their approach was to combine both the sydnone moiety and a metal centre to obtain highly biologically active compounds. Even though XRD analysis was not reported on those complexes, their structure was deduced by measuring NMR, IR, ESR, electronic spectra as well as performing elemental analysis, thermogravimetric study (TGA and DTG), magnetic study and mass spectroscopy. The antibacterial and antifungal activity of the ligands and complexes were tested against two bacteria, Escherichia coli and Bacillus cirroglagellous, and two fungi, Aspergillus niger and Candida albicans. In all cases, the complexes were found more active than the parent ligand. Amongst all, the copper complexes showed better antifungal activity than the others.

\section{Comparison of crystallographic data}

Fig. 4 shows selected structures obtained by X-ray diffraction, in which the sydnone heterocycle is directly coordinated to the metal. Depending on the ligand and the metal, different structures were obtained. Indeed, for compound 21, which was synthesized by oxidative addition of corresponding bromosydnone to palladium (Scheme 7), ${ }^{10}$ a square planar arrangement is observed. Additionally, it should be noted that in 21,

Table 2 Selected bond distances and angles for compounds 30-36

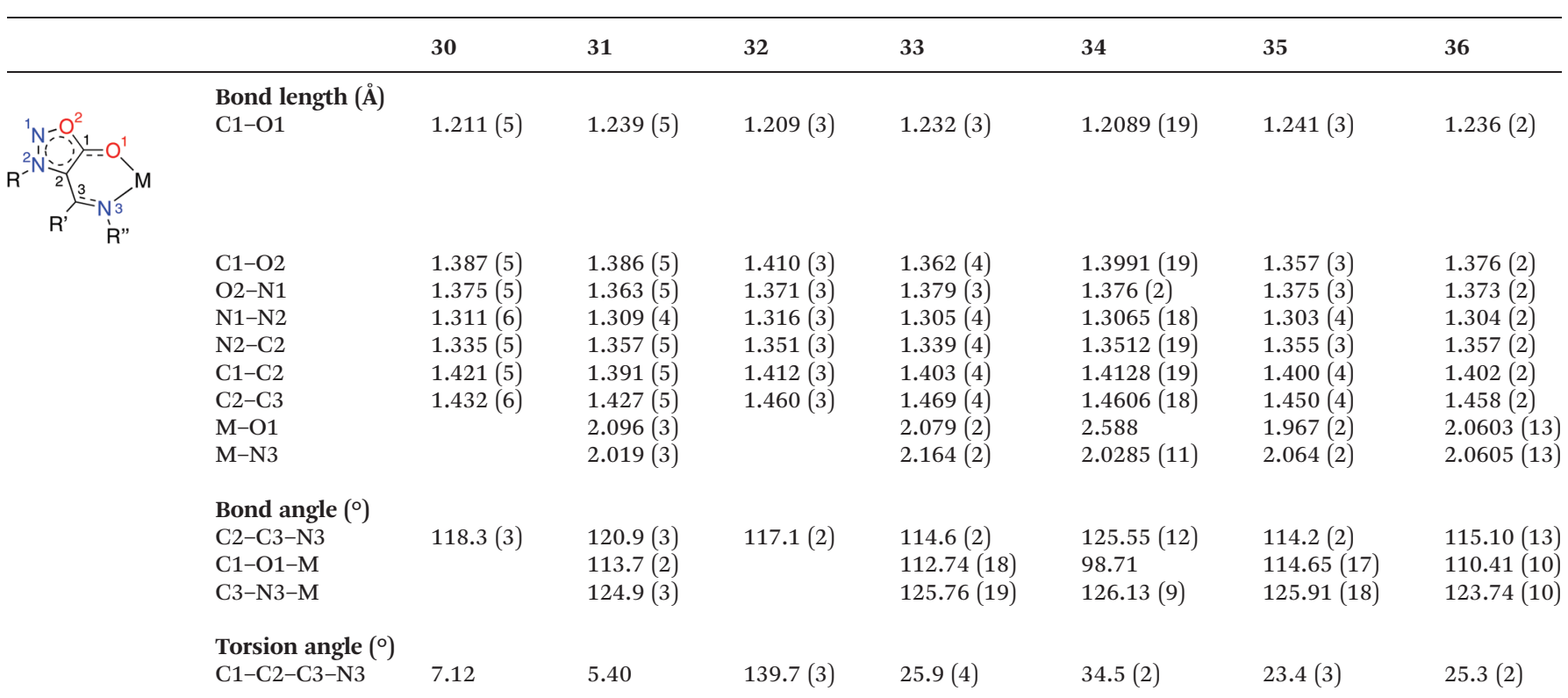


the sydnone-palladium bond is $1.9991 \AA$, as for the $\mathrm{Pd}-\mathrm{C}$ bond in palladium complexes featuring NHC ligands (Table 1). Concomitantly, the $\mathrm{N} 2-\mathrm{C} 2$ and $\mathrm{C} 1-\mathrm{C} 2$ bonds in 21 are longer than in parent sydnone 42. Complexes 33-36 were prepared by coordination of bidentate ligand 32, featuring a sydnone and a pyridine moiety (Scheme 11). Cobalt complex 33 adopts a dimeric structure, with two sydnones in cisarrangement on each cobalt atom. Copper complexes 34 and 35 display an octahedral geometry with the two sydnone ligands in trans. Zinc complex 36 exhibits a tetrahedral geometry with only one sydnone ligand. Interestingly, the C1-O1 bond has a double bond character in all the complexes, and stretches upon coordination except for copper complex 34, for which the bond length is similar to the one in ligand $\mathbf{3 2}$ (Table 2). This is in correlation with the $\mathrm{Cu}-\mathrm{O} 1$ distances, which are of $2.588 \AA$ and $1.967 \AA$ in copper complexes 34 and 35 , respectively, and bond angles $\mathrm{C} 1-\mathrm{O} 1-\mathrm{Cu}$. In compound 34, this angle is about $98.71^{\circ}$ while in complex 35 it is $144.65^{\circ}$. However, even if there is a weak interaction between the exocyclic oxygen of the sydnone and the copper centre in 34, the chelation is present as shown by the torsion angle $\mathrm{C} 1-\mathrm{C} 2-\mathrm{C} 3-\mathrm{N} 3$, with a value of $34.5^{\circ}$ while in the free ligand, it is $139.7^{\circ}$.

\section{Conclusions}

Even if sydnones attracted much attention in the 1960s, their interest was renewed in the last 10 years with their use in modern heterocycle synthesis. On the other hand, only scarce examples demonstrated that sydnone could act as ligand in coordination structures. If some examples were developed with a metalation of the sydnone at position $\mathrm{C}_{4}$, mainly for further synthetic purposes, fewer reports deal with the involvement of other sydnone atoms in the coordination of the metal. These compounds may be of interest either for their reactivity, including catalysis, or for their electronic or biological properties. One can expect promising future developments with new molecules involving a sydnone moiety in their structures, whether by new coordination modes, by the involvement of a variety of metals or by the contribution of the electronic properties of the mesoionic compound.

\section{Conflicts of interest}

There are no conflicts to declare.

\section{Acknowledgements}

The Université de Montpellier and Centre National de la Recherche Scientifique (CNRS) are acknowledged for funding. We would like to thank the reviewers for their fruitful comments that contributed to the improvement of this manuscript.

\section{Notes and references}

1 J. C. Earl and A. W. Mackney, J. Chem. Soc., 1935, 899.

2 (a) F. H. C. Stewart, Chem. Rev., 1964, 64, 129; (b) E. Decuypère, L. Plougastel, D. Audisio and F. Taran, Chem. Commun., 2017, 53, 11515.

3 D. L. Browne and J. P. A. Harrity, Tetrahedron, 2010, 66, 553.

4 (a) W. D. Ollis, S. P. Stanforth and C. A. Ramsden, Tetrahedron, 1985, 41, 2239; (b) C. A. Ramsden, Tetrahedron, 2013, 69, 4146.

5 http://goldbook.iupac.org/terms/view/M03842.

6 C. Tin-Lok, J. Miller and F. Stansfield, J. Chem. Soc., 1964, 1213.

7 W. Hill and L. E. Sutton, J. Chim. Phys., 1949, 46, 244.

8 L. E. Orgel, T. L. Cottrell, W. Dick and L. E. Sutton, Trans. Faraday Soc., 1951, 47, 113.

9 G. Subramanian, P. von R. Schleyer and H. Jiao, Angew. Chem., Int. Ed. Engl., 1996, 35, 2638.

10 S. Wiechmann, T. Freese, M. H. H. Drafz, E. G. Hübner, J. C. Namyslo, M. Nieger and A. Schmidt, Chem. Commun., 2014, 50, 11822.

11 (a) H. Bärnighausen, F. Jellinek, J. Munnik and A. Vos, Acta Crystallogr., 1963, 16, 471; (b) W. E. Thiessen and H. Hope, J. Am. Chem. Soc., 1967, 89, 5977; (c) M. Barber, S. J. Broadbent, J. A. Connor, M. F. Guest, I. H. Hillier and H. J. Puxley, J. Chem. Soc., Perkin Trans. 2, 1972, 1517; (d) J. M. Fan, Y. Wang and C. H. Ueng, J. Phys. Chem., 1993, 97, 8193.

12 (a) J. Hasek, J. Obrda, K. Huml, S. Nespurek, H. Chojnacki and M. Sorm, Acta Crystallogr., Sect. B: Struct. Crystallogr. Cryst. Chem., 1978, 34, 2756; (b) J. Hasek, J. Obrda, K. Huml, S. Nespurek and M. Sorm, Acta Crystallogr., Sect. B: Struct. Crystallogr. Cryst. Chem., 1979, 35, 2449; (c) C.-H. Ueng, Y. Wang and M.-Y. Yeh, Acta Crystallogr., Sect. C: Cryst. Struct. Commun., 1987, 43, 1122; (d) C.-H. Ueng, Y. Wang and M.-Y. Yeh, J. Chin. Chem. Soc., 1987, 34, 105; (e) S. J. Prathap, S. R. Nooji, B. Kalluraya and T. N. G. Row, Acta Crystallogr., Sect. E: Struct. Rep. Online, 2007, 63, o3976; $(f)$ J. H. Goh, H.-K. Fun, Nithinchandra and B. Kalluraya, Acta Crystallogr., Sect. E: Struct. Rep. Online, 2010, 66, o2198; (g) F. Albota, C. Drăghici, M. R. Caira and F. Dumitrascu, Tetrahedron, 2015, 71, 9095;

(h) N. Pétry, T. Vanderbeeken, A. Malher, Y. Bringer, P. Retailleau, X. Bantreil and F. Lamaty, Chem. Commun., 2019, 55, 9495.

13 J. Applegate and K. Turnbull, Synthesis, 1988, 1011.

14 W. Baker, W. D. Ollis and V. D. Poole, J. Chem. Soc., 1950, 1542.

15 S. Specklin, E. Decuypere, L. Plougastel, S. Aliani and F. Taran, J. Org. Chem., 2014, 79, 7772.

16 J. M. Tien and I. M. Hunsberger, J. Am. Chem. Soc., 1961, 83, 178.

17 K. Turnbull, T. L. Blackburn and D. B. McClure, J. Heterocycl. Chem., 1994, 31, 1631.

18 H. J. Tien and Y. K. Lee, J. Chin. Chem. Soc., 1988, 35, 63. 
19 V. N. Kalinin and P. M. Se, J. Organomet. Chem., 1988, 352, C34.

20 (a) V. N. Kalinin, D. N. Pashchenko and M. S. Phan, Mendeleev Commun., 1992, 60; (b) I. y. a. Cherepanov, D. D. Bronova, E. Y. Balantseva and V. N. Kalinin, Mendeleev Commun., 1997, 93.

21 (a) V. N. Kalinin, P. M. Se and P. V. Petrovskii, J. Organomet. Chem., 1989, 379, 195; (b) L. N. Morozova, L. S. Isaeva, P. V. Petrovskii, D. N. Kravtsov, S. P. Minh and V. N. Kalinin, J. Organomet. Chem., 1990, 381, 281.

22 K. Turnbull, J. Heterocycl. Chem., 1985, 22, 965.

23 V. N. Kalinin, F. M. She, V. N. Khandozhko and P. V. Petrovskii, Russ. Chem. Bull., 2001, 50, 525.

24 H. Liu, D. Audisio, L. Plougastel, E. Decuypere, D.-A. Buisson, O. Koniev, S. Kolodych, A. Wagner, M. Elhabiri, A. Krzyczmonik, S. Forsback, O. Solin, V. Gouverneur and F. Taran, Angew. Chem., Int. Ed., 2016, 55, 12073.

25 A.-L. Luecke, S. Wiechmann, T. Freese, Z. Guan and A. Schmidt, Z. Naturforsch., B: J. Chem. Sci., 2016, 71, 643.

26 A.-L. Luecke, S. Wiechmann, T. Freese and A. Schmidt, Synlett, 2017, 28, 1990.

27 (a) T. Freese, A.-L. Lücke, C. A. S. Schmidt, M. Polamo, M. Nieger, J. C. Namyslo and A. Schmidt, Tetrahedron,
2017, 73, 5350; (b) T. Freese, J. C. Namyslo, M. Nieger and A. Schmidt, $R S C$ Adv., 2019, 9, 4781.

28 S.-T. Lin, H.-S. Cheo, L.-S. Liu and J.-C. Wang, Organometallics, 1997, 16, 1803.

29 S.-T. Lin, H.-S. Choe, L.-S. Liu and J.-C. Wang, J. Organomet. Chem., 2000, 610, 1.

30 S. T. Lin, K. J. Peng, T. M. Barclay and A. W. Cordes, Inorg. Chim. Acta, 2001, 321, 89.

31 S. T. Lin, H. S. Cheo, B. I. Chen and Z. Y. Own, Heteroat. Chem., 1998, 9, 549.

32 M.-H. Shih, J.-C. Chen, G.-L. Lin, T.-T. Lin and M.-H. Sun, J. Pharm. Pharmacol., 2014, 66, 73.

33 A. Beillard, X. Bantreil, T.-X. Métro, J. Martinez and F. Lamaty, Chem. Rev., 2019, 119, 7529.

34 S. M. Lee, US3549639A, 1970.

35 C. S. Lin, A. Yeh, T. Y. Liu, K. S. Kwan, D. J. Hodgson and H. J. Tien, Inorg. Chim. Acta, 1992, 192, 81.

36 C.-H. Shi, S.-T. Wang, S.-Y. Yang, A. Yeh and H.-J. Tien, J. Chin. Chem. Soc., 1998, 45, 77.

37 T. M. Cooper, B. C. Hall, D. G. McLean, J. E. Rogers, A. R. Burke, K. Turnbull, A. Weisner, A. Fratini, Y. Liu and K. S. Schanze, J. Phys. Chem. A, 2005, 109, 999.

38 M. A. Phaniband, S. D. Dhumwad, J. J. Jogul and P. G. Avaji, Main Group Chem., 2008, 7, 285. 